\title{
Inclusion as an environmental imperative of educational activity in university, secondary and preschool education
}

\author{
Galina Stepanova ${ }^{1}$, Anastasia Demchuk ${ }^{2}$, Anna Tashcheva ${ }^{3}$, Svetlana Gridneva ${ }^{3}$, \\ Julia Yakovleva ${ }^{2}$, Yaroslav Zaichikov ${ }^{4}$, and Mariam Arpentieva ${ }^{2, *}$ \\ ${ }^{1}$ Laboratory for Innovative Educational Technologies, Surgut State Pedagogical University, 628417, \\ Surgut, Khanty-Mansi Autonomous Area -Yugra, Russian Federation \\ ${ }^{2}$ Surgut State University, 628412, Surgut, Khanty-Mansi Autonomous Area - Yugra, Russian \\ Federation \\ ${ }^{3}$ Academy of Psychology and Pedagogy of the South Federal University, 344006, Rostov Region, \\ Rostov-on-Don, Russian Federation \\ ${ }^{4}$ M.M. Speranskiy Law Institute, A.G.and N.G. Stoletovs Vladimir State University, 600000, \\ Vladimir, Russian Federation
}

\begin{abstract}
The environmental imperative in education has given rise to a number of approaches and models, including the model of inclusive education, which requires the unification of students with different educational needs and capabilities within one educational system. The heuristic potential of such studies is significant, although very little understood. The ecological approach to understanding inclusiveness has significant practical significance and value: the ecological imperative helps to identify and implement the most effective and productive ways of transforming existing problems, without sacrificing either the tasks of development and movement forward, or the tasks of preserving the existing ones. At each stage of education inclusion as an ecological imperative presupposes certain accents. In preschool education, inclusion is the creation of an environment in which children can become aware of the differences between each other, related to their individual characteristics. In school education, children and adolescents can realize and feel the differences in the forms and strategies for building interactions and relationships between people, as well as the existence of different strategies, forms and types of learning activity and learning relationships. In university education, young individual can sense the differences that exist in the forms and relationships of professional and career activity.
\end{abstract}

\section{Introduction}

The modern world is actively changing. Changes in the modern world are often described in terms of increasing complexity and diversity, social fragmentation and alienation, a-culture and the renaissance of traditional cultures and forms of relations,

\footnotetext{
*Corresponding author: mariam_rav@mail.ru
} 
digitalization, biotechnology and humanization $[1,2,3,4]$. These inherently multidirectional tendencies give rise to a huge number of social and other problems that require, in varying degrees, immediate and large-scale solutions, and, in fact, numerous, conscious and directed transformations. Among the many concepts used as decisive ones for overcoming these problems and choosing the vector of directions for transforming difficult and crisis situations, the concept of environmental friendliness is often used. The ecological imperative, first understood as the imperative of caring for nature, is now a system of requirements and guidelines for man's concern for the harmony and transparency of man's relations with the natural world and the world of culture, with the world around him / her and with himself / herself $[5,6,7,8]$. This imperative permeates all spheres of modern life of society and man, giving rise to new approaches, concepts and technologies. In education, the ecological imperative has given rise to a number of approaches and models, for example, the model of lifelong education, which fixes the importance and naturalness for a person as a social, developing, unique, life-long education. "Complementary" to it was the competence-based approach, reflecting the importance of mastering a certain system of competencies (a set of knowledge and skills): at each stage of personal, interpersonal and educational-professional formation and development of an individual, in each of the areas of his / her improvement (intimate-personal and family, professional / labour, hobby, sports, etc. "career"). It also gave birth to a model of subjective, individualized or "personalized" education, focused on the individuality of students. It also gave rise to a complementary model of inclusive education, requiring the inclusion of students with different educational needs and capabilities within the same educational system $[9,10,11,12]$. Each of these and other areas of implementation of the ecological imperative has become the subject of numerous studies, however, there are few studies devoted to their understanding as ecological ones. At the same time, the heuristic potential of such studies is very significant. In addition, it has significant practical significance and value: the ecological imperative helps to identify and implement the most effective and productive ways of transforming existing problems, without sacrificing either the tasks of development and movement forward, or the tasks of preserving the existing ones. Unfortunately, in modern science and practice, ecology is often reduced to the essentially anti-ecological principle of "sustainable development", emphasizing the importance of "stability": in nature and culture, stability exists in a spirit of variants, including as a stable manifestation of stagnation ("stagnation") and a stage on the way to collapse and as a small "plateau" on the way to development. As soon as we combine "sustainability" and "development", we start talking about stagnation. The goal of education, even if we take into account its function of preserving and transmitting culture, is still development: educational programs (content), methods (forms, technologies) are constantly being updated and changed. So, referring to the concepts of anabolism and catabolism (exchange in a living organism), researchers write that "The paradigm of anabolism of society suggests that its main task is not the fact of development as such, but following the loop of the quality of life while conserving resources on a planetary scale (in avoiding the catabolism of society, the processes of its destruction and simplification)" [13]. This paradigm is closely related to the "marketing" understanding that people with special needs (people with disabilities) are primarily interested in inclusion, and normotypical individuals act only as a means of satisfying these needs $[14,15,16]$. This, of course, violates the requirement to include a child with disabilities or other features (non-standard, queer) into the educational environment without infringing on the rights of healthy (normotypical) students. Inclusion is about creating an adaptive environment that acts as a melting pot. It is characterized by the suppression of "traditional" patterns of behaviour in children, adolescents and young men as one of the repressive practices of managing diversity. However, the orientation towards adaptation and assimilation (both on the part of people with disabilities and other 
inclusive groups, and on the part of the groups of the social majority who accept them), on the essentialist separation of "right" and "wrong" values and attitudes, behaviour / interaction models, identities and traditions, to "correct" the "wrong" and assimilate the "right", turns out to be fundamentally ineffective in the context of new challenges (replacing the internationalization of transnationalization) and the goals of education and life of the interacting parties $[17,18]$. This is only a source of "differentialist racism" [19], which, while declaring "noble" goals (preserving diversity, tolerance, security, inclusion), strengthens and fixes intergroup boundaries and, accordingly, practically excludes the very possibility of inclusion, proclaimed by the ideal modern education at its various levels. "Without a conscious rejection of the strategy of assimilation of minorities, it is hardly possible to resolve issues of protecting individual freedom, levelling group statuses and building an "agonal dialogue" (Tully 2008), during which people of different groups are involved in direct discussion [20,21]. The preference for parity, dialogical integration is a guarantee of protecting individual freedom, overcoming exclusion and injustice, and "leveling" group statuses [21]. The concept of exclusion or social exclusion by R. Lenoir describes the state of many socially unprotected, rejected (stigmatized and subjected to bullying and alienation, passing through discrimination and deprivation) minority groups [22]. The most typical is the understanding of social exclusion as a phenomenon denoting a state of total social distress, restriction or lack of access to necessary and sufficient resources, a person's falling out of social structures, shifting to the "social bottom" as a result of a "chain reaction" of breaking several or all social systems and relations, (A. Giddens, I. A. Makeeva, R. Abrahamson, R. Atkinson, F. Farrington, S. Paugam, A. Power, W. Wilson) [23, 24, 25]. Going beyond the "exchange" model of "sustainable development" allows us to overcome the pragmatism of inclusion as "education for the disabled", and in combination with the "paradigm of society empathy", to note the dialogical, development-oriented nature of relations between different social groups and individuals. Empathy as a personal and social phenomenon encourages development, selfimprovement and mutual improvement, and does not reduce it to the "quality of life", its consumption (including the consumption of educational services, subjects of education and oneself), as the marketing approach of "sustainable development" suggests. Like the ecological imperative, the educational imperative, its central task, is associated precisely with development $[26,27]$. The ecological imperative affirms the importance of providing the opportunity for the natural world and the world of culture to live and develop as they deem it necessary to develop, without cancelling or replacing the "natural" evolution or even involution of natural and cultural systems with ideas about development formulated by man or individual groups of people or other subjects.

\section{Research methodology}

The purpose of the study is to analyze inclusion as the implementation of the environmental imperative in the field of educational activities in university, secondary and preschool education. The research method is a phenomenological theoretical analysis of inclusion as a manifestation of the ecological imperative in educational activities in university, secondary and preschool education.

\section{Research results}

Inclusion in education acts as one of the forms of implementation of the ecological imperative, including in relation to humans $[9,10,11,12,28]$. In the educational activities of universities, secondary schools and preschool institutions, it presupposes such an 
organization of educational and educational processes that would allow children, adolescents, youths and adults of different subcultures to interact with each other, realizing their internal needs for mutual assistance and service, for self-improvement and mutual improvement, in the exchange of knowledge and skills (competencies), experience, and in the appropriation and creation (research as "learning from") experience and competencies (L. Barton, J. Deppler, E. Doris, T. Loreman, U Sailor, E. K. Sliker, D. Harvey, S.V. Alekhina, M.R. Arpentieva, D.V. Zaitsev, E.N. Kutepova, N.N. Malofeev, E.R. YarskayaSmirnova).

O.V. Lesher, L.V. Demenina (2015) note that "inclusive education is a long-term strategy that requires patience and tolerance, systematicity and consistency, continuity, and an integrated approach for its implementation. Inclusion involves the involvement in the learning process of each object of the educational process (preschool pupils, schoolshildren, students) with the help of an educational program that matches his / her abilities, as well as meeting individual educational needs, providing special conditions" [29]. A.L. Boyko and her co-authors write that "inclusive education is a multi-stage education system that includes different groups of clients with social and functional differences" aimed at (re)habilitation, (re) socialization in the process of education and upbringing in the context of professionalization (Boyko et al., 2020) [30].

General principles of organizing an inclusive educational environment: include 1) the principle of early inclusion in an inclusive environment, which makes it possible to form and develop abilities for social interaction, 2) the principle of active cooperation between the work of parents and an interdisciplinary team of specialists, the poly-subject nature of educational space-time, which ensures the completeness of support for the processes of education and training, 3) the principle of individual orientation of education, 4) the principle of the development of the educational environment, including the model of an educational institution (kindergarten, school, university), 5) the principle of the priority of education (socialization): the formation and development of social competencies and experience, including partnership, 6) socially and psychologically safe, barrier-free environment, 7) development of competence and enrichment of the palette of vectors of professional development of specialists and other subjects of education [31, 32, 33, 34]. M. A. Suchkov, L. Florian and J. Sprat, M. Robo, P. Pandit note that inclusive practice is needed in order to identify and correct barriers to social acceptance, participation and education of children, adolescents, youths, adults with certain features of functioning or development., consider it important to take into account and take for granted the differences of the subjects of education, the faith of teachers in their abilities and qualifications, as well as the continuous search and creativity of effective ways of working with different students $[35,36,37,38]$. The world community is moving away from a narrow understanding of inclusion as interaction with people with disabilities, and comes to widespread acceptance of inclusion, when society becomes diverse, with the absence of segregation in it along various grounds ... which is the ideological basis of inclusion. Inclusion as a special, progressive worldview reflects the psychosocial maturity of society, includes well-thoughtout structures for the interaction of the student's family with society and with other families, schools and other social institutions [39, 40].

At each stage of educational relations, inclusion as an ecological imperative presupposes certain accents:

1) in preschool education, one of the goals of which is the formation of the individual as a person, inclusion is the creation of an environment in which children can realize and feel each other's differences as personal differences associated with differences in the psychophysiological type, with differences in the experience of family and ethnospecific education and training and other factors. Inclusion is the creation of an environment in 
which children can recognize and comprehend personal differences in learning outcomes and processes;

2) in school education, one of the leading goals of which is the formation of an individual as a partner, children and adolescents can realize and feel the differences in the forms and strategies of building interactions and relationships between people associated with the differences in those systems of relations in which a person is included, including a person having a disability. Another goal of school education is the formation of the individual as a student, awareness of the existence of different strategies, forms and types of educational activity and educational relations;

3 ) in university education, the leading goal of which is to become an individual as a future professional, young men and women can feel the differences that exist in the forms and relationships of professional and career activity. Boys and girls may be aware of the challenges associated with the transition from academic to professional activities.

Table 1. Educational inclusion as an ecological imperative.

\begin{tabular}{|c|c|c|c|}
\hline $\begin{array}{c}\text { Stages of } \\
\text { educational } \\
\text { relations }\end{array}$ & Goals & Life content & Educational content \\
\hline $\begin{array}{l}\text { Preschool } \\
\text { education }\end{array}$ & $\begin{array}{l}\text { formation of } \\
\text { the individual } \\
\text { as a person }\end{array}$ & $\begin{array}{l}\text { inclusion is the creation of an } \\
\text { environment in which } \\
\text { children can realize and feel } \\
\text { each other's differences as } \\
\text { person }\end{array}$ & $\begin{array}{l}\text { inclusion is the creation of } \\
\text { an environment in which } \\
\text { children can recognize and } \\
\text { comprehend personal } \\
\text { differences in learning } \\
\text { outcomes and processes }\end{array}$ \\
\hline $\begin{array}{l}\text { School } \\
\text { education }\end{array}$ & $\begin{array}{l}\text { formation of } \\
\text { an individual } \\
\text { as a partner } \\
\text { and a student }\end{array}$ & $\begin{array}{l}\text { children and adolescents can } \\
\text { realize and feel the } \\
\text { differences in the forms and } \\
\text { strategies of building } \\
\text { interactions and relationships } \\
\text { between people }\end{array}$ & $\begin{array}{l}\text { awareness of the existence } \\
\text { of different strategies, } \\
\text { forms and types of } \\
\text { educational activity and } \\
\text { educational relations }\end{array}$ \\
\hline $\begin{array}{l}\text { University } \\
\text { education }\end{array}$ & $\begin{array}{l}\text { to become a } \\
\text { future } \\
\text { professional }\end{array}$ & $\begin{array}{l}\text { young men and women can } \\
\text { feel the differences that exist } \\
\text { in the forms and relationships } \\
\text { of professional and career } \\
\text { activity }\end{array}$ & $\begin{array}{l}\text { boys and girls may be } \\
\text { aware of the challenges } \\
\text { associated with the } \\
\text { transition from academic to } \\
\text { professional activities }\end{array}$ \\
\hline
\end{tabular}

In preschool education, inclusion is often more or less natural: if at this stage of human development he or she is faced with a lack of practices of exclusion and isolation, including children with disabilities or children with developed creative or other abilities, then he can not only realize and feel the differences each other as personal differences associated with differences in the psychophysiological plan, with differences in the experience of family and ethnospecific education and training and other factors, but also to be involved in an active exchange with other children and their experience. As a rule, the influence of this experience is often underestimated: the concept of development, reflected in the metaphor of "playing by the side", preschool children do not appear as subjects involved in meaningful relationships with each other. Indeed, relationships with parents and preschoolers are more significant, structuring the life experience of a preschooler. However, children are no less sensitive and appreciate the experience of interacting with peers: even examples of "status therapy" associated with the transfer of a child to an older or younger group of preschoolers to correct behavioural and attitudinal disorders towards themselves, other children, towards adults, speak of the great importance of relationships with other children, the importance of comprehending their "otherness", different from oneself. At the stage of preschool education, it is already possible to form and initially implement a personal educational trajectory, the subject specificity of ideas about oneself 
and the world, their own values of life and spiritual and moral guidelines, including in relation to children, in some way different from the main "mass" of normotypical representatives. Individualization of the educational environment of preschool educational institutions is possible and productive provided that it transforms in accordance with the subtle and precise differentiation of educational and other needs and capabilities of the child, manifested in the characteristics of individual psychosocial development [41], as well as orientation towards "human-like" education in general [42]. The mechanism of individualization of the educational environment is the creation and transformation of inclusive environmental complexes, which involves a reflexive analysis of the components of the educational environment and activities, interdisciplinary interaction of specialists at all stages of psychological and pedagogical support of students with disabilities [43, 44, 45].

E. L. Ushakova notes that inclusion is a process of education and upbringing, in which all students are included in the general education system and are considered students of a general education institution that takes into account their special educational needs. Inclusive education is based on an ideology that excludes any discrimination against people, guarantees equal treatment for all, but creates special conditions for students with special educational needs [46, p. 291] is not a "know-how", a discovery of our time. Although the idea of integrating the education of children with disabilities in physical and mental development with normally developing children is associated with the middle of the twentieth century, the introduction of the concept of "inclusive education" in Russia took place only in 2012, and the first experiences of inclusive education are attributed here to the Scandinavian countries, but the history of special education shows that already in the first decades of the 19th century, the problem of general education for typical and atypical children was the subject of scientific research and practical development, teaching practice in a number of European countries (A. Blanchet, S. Geinik, I. G. Pestalozzi, and, further M. Montessori, N. Benck, B. Nirier, B. Person, F. Galton, J. Pereira, J. Itard, E. Seguin, G. Hanselmann). I.P. Pavlov made an important and, in fact, an ecological remark about the education of people with disabilities: "... nothing remains motionless, unyielding, and everything can always be achieved, changed for the better, if only the appropriate conditions are fulfilled" [47]: all people are different, but all people can learn and be trained, just like everyone can be brought up. Yu.V. Selivanova and D.V. Zaitsev note that inclusive culture from the very beginning became a culture of diversity and inclusion (D\&I) $[48,49,50,51]$.

In school education, inclusion may already be difficult: if at the early stages of a person's development he / she faced the experience of segregation and exclusion, if in his communication and relations with the world were not present "strange", unusual, different from the normotypical children and adults, then the inclusive experience can become painful. From an environmental point of view, this experience is to a significant extent limited and "unnatural": people who do not have normotypical characteristics of the body, psyche and values can be perceived as threatening / dangerous, alien / not people, incomprehensible. Partnerships in this context can develop in a very isolated and deformed way: for example, in modern education there is an example of a "strategic" learning style, when a student who does not implement a "deep" approach to learning masks its absence and his / her choice of a "superficial" learning by "grind" and / or joining a successful child, communication with whom guarantees him / her a high status in the eyes of teachers, parents and classmates. Thus, within the framework of exclusive school education, it is difficult for the individual to become a student, his awareness of the existence of different strategies, forms and types of educational activity and educational relations.

Inclusion in university education activates and enriches the processes and results of the formation of an individual as a future professional. Thanks to inclusion, young men and 
women can experience the differences that exist in the forms and relationships of professional and career activity, even in such "extreme" situations, such as a situation of significant disability of a student with a disability [52]. They can gain experience in coping and overcoming limitations, which is very important for them as people entering the "big life", moving up the career ladder and the ladder of professional development. In addition to the experience of coping, the experience of mutual assistance / care and service is extremely important: a professional as a subject of labor is a subject that provides assistance, cooperates with other specialists and a subject that implements service. Professional deformations of many specialists are associated with the fact that they are carried away by their own professional and career tasks, ignoring the "world of professionals" and the world of relations outside of professional activity. Inclusion allows these problems to be minimized (prevention), overcome (correction and development) or rethinking (positive behavior, Scott et al., 2007) [53]. The tasks of university inclusion are the acquisition of higher education by persons with socially functional differences - on the one hand, and the development of subjectivity and internality in their social and professional activities [30]. Inclusive higher education fulfills truly global goals in relation to society and the world.

D.A. Ivanov analyzed the environmental problems of inclusion, noting that since some children with disabilities are delayed in development (both as a result of the late integration of the child and as a result of the initial presence of significant deviations), a problem arises: if children are separated by more than one stage of development, then their mutual socialization is impossible. Such children will not want and / or will not be able to interact productively and effectively with each other. Therefore, full inclusion is not applicable in all situations, it is necessary to involve other forms of education in order to ensure the development of all children without exception [55]. The key principles of correctional and inclusive education include, therefore, a number of principles based on the research of L.S. Vygotskiy, including the idea of the zone of proximal development, and other ecological ideas $[21,40,47]$. So, one of the leading principles of correction, including in special and inclusive education, suggests that educational progress is associated with an orientation towards the potential capabilities of individuals, and not at their limitations, towards development, and not towards compensation, towards overcoming and creativity, and not just for adaptation and "sustainability". E. Horn, D. Mitchell, Yu. A. Shulekina, D. E. Novikova $[56,57,58]$ note that inclusive organizational culture includes all actors, giving them the opportunity to "feel valued for organizing and creating a sense of belonging". Here we can use the approach of special schools, modernized, taking into account the ideas of inclusion: using the framework of special education, including special schools and special classes ("classes of intensive correction", "transition classes"), it is possible and necessary to create conditions for the contact of children, adolescents and young men with disabilities with ordinary students, including in an extra-educational environment. I.A. Erina and colleagues [59, p. 169] also describe the phenomenon of "reverse inclusion": normotypical children, adolescents, and young individual come to certain lessons / classes in correctional classes, where they study and are brought up together with students with disabilities. This approach will help children integrate, even when separated in a number of other, isolating situations. You can also organize training focused on the inclusion in one group (educational team) of children who are at neighboring stages (stages) of development, but you need to understand that the development of children with and without disabilities occurs in different ways. Therefore, competent and attentive teachers are needed who are able and willing to notice these differences, take into account, harmonize (reconcile) [60, 61].

It is also important to take into account the natural processes of group formation, usually leading to the division of the study group into a subgroup of special children and a 
subgroup of everyone else, up to stigmatization and bullying (which does not correspond to the ideals of inclusion). Therefore, we need teachers or psychologists who are ready and able to organize and correct interaction, to instill the ideas of equality of people, regardless of their characteristics: in a children's team, without intentional and constant external influence, an inclusive environment is not self-sustaining. It also does not exist in a more mature group, where the ideas (culture) of inclusion have not been formed. Therefore, it is so important to form and develop an inclusive culture of society from the earliest stages of human development. For example, this can be done by instilling ideas of tolerance and acceptance, cooperation and mutual assistance, inclusion and compatibility at an extremely early age - for example, in kindergartens and other preschool educational institutions. Thus, "building an inclusive environment should begin at an early stage in the life of children, before primary school ... work on introducing an inclusive environment should be carried out with parents as well" [55].

\section{Conclusion}

Among the many concepts used as decisive ones for overcoming urgent problems of social development and choosing the vector of directions for transforming difficult and crisis situations, the concept of environmental friendliness is often used. The ecological imperative, first understood as the imperative of caring for nature, is now a system of requirements and guidelines for man's concern for the harmony and transparency of man's relations with the natural world and the world of culture, with the world around him and with himself. This imperative permeates all spheres of modern life of society and man, giving rise to new approaches, concepts and technologies. In education, the environmental imperative has given rise to a number of approaches and models, including the model of inclusive education, which requires the inclusion of students of different educational needs and capabilities within the same educational system. The heuristic potential of such research is very significant, although so far it has been comprehended by scientists and specialists very little. In addition, the ecological approach to understanding inclusiveness has significant practical significance and value: the ecological imperative helps to identify and implement the most effective and productive ways of transforming existing problems, without sacrificing either the tasks of development and movement forward, or the tasks of preserving the existing ones. Unfortunately, in modern science and practice, ecology is often reduced to the essentially anti-ecological principle of "sustainable development", which emphasizes the importance of "stability" rather than the improvement and selfimprovement of society and individuals. Inclusion as a doctrine and as a practice, therefore, faces the problem of degeneration into attempts at adaptation and assimilation, secondary or latent exclusion. To overcome negative trends, in addition to changes in the programs of different countries and states, changes in the organizational structure of educational organizations and changes in the formation and development of an inclusive culture of society and the individual are necessary. The foundations of the culture of inclusion are laid in early childhood; the priority here belongs to the preschool educational institution. At each stage of educational relations, inclusion as an ecological imperative presupposes certain accents. In preschool education, one of the goals of which is the formation of the individual as a person, inclusion is the creation of an environment in which children can realize and feel each other's differences as personal differences associated with differences in the psychophysiological type, with differences in the experience of family and ethnospecific education and training and other factors. Iinclusion is the creation of an environment in which children can recognize and comprehend personal differences in learning outcomes and processes. In school education, one of the leading goals of which is the formation of an individual as a partner, children and adolescents can realize and feel the 
differences in the forms and strategies of building interactions and relationships between people associated with the differences in those systems of relationships in which a person is included, including a person having a disability. Another goal of school education is the formation of the individual as a student, awareness of the existence of different strategies, forms and types of educational activity and educational relations. In university education, the leading goal of which is the formation of an individual as a future professional, young men and women can feel the differences that exist in the forms and relationships of professional and career activity. Boys and girls may be aware of the challenges associated with the transition from academic to professional activities.

\section{References}

1. P. Abrahamson, Sociologisk Rapportserie 13, 77-83 (1998)

2. M.R. Arpentieva, P.B. Geraskina, S.V. Lavrinenko, T.Y. Zalavina, E.N. Kamenskaya, A.I. Tashcheva, Astra Salvensis. Revistã de istorie şi culturã (review of history and culture) VI, 2, 645-663 (2018)

3. A. Power, W. J. Wilson, Social Exclusion and the Future of Cities. London: Centre for Analysis of Social Exclusion (London School of Economics and Political Science, 2000)

4. G.A. Stepanova, A.I. Tashcheva, T.A. Markova, E.U. Shpakovskaya, M.R. Arpentieva, N.G. Bazhenova, O.V. Tokar, and M.E. Kirichkova, International Journal of Education and Information (International Journal of Education and Information (NAUN) 13, 4148 (2019)

5. M.R. Arpentieva, K.G. Kassymova, S.V. Lavrinenko, Z.I. Tyumaseva, G.V. Valeeva, O.B. Kenzhaliyev, M.B. Triyono, O.N. Duvalina, A.V. Kosov, Bulletin of National Academy of Sciences of the Republic of Kazakhstan 3(379), 11-18 (2019)

6. M.R. Arpentieva, Psychosocial support of persons with disabilities and their families (Lan, St. Petersburg, 2021)

7. G.K. Kassymova, G.A. Stepanova, O.P. Stepanova, P.V. Menshikov, M.R. Arpentieva, A.P. Merezhnikov, L.A. Kunakovskaya, International Journal of Education and Information 12, 171-176 (2018)

8. G.K. Kassymova, O.V. Tokar, A. I. Tashcheva, G.V. Slepukhina, S.V. Gridneva, N.G. Bazhenova, E.Yu. Shpakovskaya, M.R. Arpentieva, International Journal of Education and Information 13, 26-32 (2019)

9. M. Afshar Ali, Kh. Alam, B. Taylor, Sh. Rafiq, Telematics and Informatics 51, 101405 (2020) https://doi.org/10.1016/j.tele.2020.

10. A. Magyar, A. Krausz, D.I. Kapas, A. Habok, Heliyon 6, 1 (2020) https://doi.org/10.1016/j.heliyon.2020.e03851

11. S. Schwab, C. Zurbriggen, M. Venetz, Journal of School Psychology 82, 1-16 (2020) https://doi.org/10.1016/j.jsp.2020.07.003

12. F. Stanford, Journal of the National Medical Association 112(3), 247-249 (2020) https://doi.org/10.1016/j.jnma.2020.03.014

13. V.D. Malygina, K.A. Antoshina, TsITIS 4(26), 35-48 (2020)

14. I. Genta, B. Aigner, B. Beijer, J. Jepsen, G. Rocca, Progress in Aerospace Sciences 119(1) (2020) https://doi.org/10.1016/j.paerosci.2020.100642

15. K.S. Matsiori, Economic Analysis and Policy 66, 335-344 (2020) https://doi.org/10.1016/j.eap.2020.02.010 
16. C. B. Olalla, A. Merino, The International Journal of Management Education 17(2), 239-253 (2020) https://doi.org/10.1016/j.ijme.2019.02.006

17. R.D. Grillo, Anthropological theory 3(2), 157-173. (2003)

18. J. Lie, Contemporary Sociology 24(4), 303-306 (1995)

19. E. Balibar, I. Wallerstein, Race, nation, class. Ambiguous identities (Logos, Moscow, 2004)

20. J. Tully, Public Philosophy in a New Key (Cambridge University Press, Cambridge, 2008)

21. M.A. Kozlova, I.S. Mikheev, Journal of Social Policy Research 18(4), 657-672 (2020)

22. I.A. Makeeva, A.I. Herzen, Bulletin of the Russian State Pedagogical University 198, 45-55 (2020)

23. R. Atkinson, Urban Studies 37, 1037-1055 (2000)

24. Ch. Gore, Social Exclusion: Rhetoric Reality Responses (International Institute for Labour Studies, Geneva, 1995 )

25. S. Paugam, Elements of a comparative research perspective on poverty in European societies (Macmillan, London, 1996)

26. M.R. Arpentieva, R.R. Gasanova, T.L. Khudyakova, O.P. Stepanova, O.V. Tokar, O.N. Duvalina, Bulletin of the N.I. Lobachevskiy Nizhny Novgorod University, Series: Social Sciences 3(59), 154-165(2020)

27. M.R. Arpentieva, T.L. Khudyakova, O.V. Tokar, E.Yu. Shpakovskaya, O.P. Stepanova, N.G. Bazhenova, Bulletin of the N.I. Lobachevskiy Nizhny Novgorod University, Series: Social Sciences 4(56), 175-181 (2019)

28. P. Stroebel, International Social Science Journal 71(1), 5-20 (1996)

29. O.V. Lesher, L.V. Demenina, Modern problems of science and education 1, 1 (2020) www.science-education.ru/121-18603

30. A.L. Boyko, T.E. Maltseva, T.S. Shcherbakova, Yu.M. Udovenko, Human. The science. Society 2(4), 170-184 (2020)

31. V.D. Bayramov, A.V. Gerasimov, Psychological-Educational Studies 11(3), 15-25 (2019)

32. T. Booth, M. Ainscow, Index for inclusion: Developing learning and participation in schools (Centre for Studies on Inclusive Education, Bristol, United Kingdom, 2020)

33. N.M. Nazarova,, T.G. Bogdanova, Pedagogy of inclusive education (INFRA-M, Moscow, 2019)

34. H. Silver, Framing Social Inclusion Policies. Draft Background Paper for the World Bank Social Development Department's Flagship Study on Social Inclusion (New York: NY Publ., 2012) https://papers.ssrn.com

35. P. Pandit, International Journal of Academic Research and Development 2(5), 665-673 (2017)

36. M. Robo, Academicus International Scientific Journal 10, 181-191 (2014)

37. J. Spratt, L. Florian, Revista de Investigación en Educación 11(3), 133-140 (2013)

38. M.A. Suchkov, Modern science: actual problems of theory and practice. Series: human sciences 6, 93-98 (2020) https://doi.org/10.37882 / 2223-2982.2020.06.32

39. Ch. Imms, B. Adair, D. Keen, A. Ullenhag, P. Rosenbaum, M. Granlund, Developmental medicine and child neurology 58(1), 29-38 (2016) https://doi.org/10.1111/ dmcn.12932 
40. T.V. Volkova, T. Henchel, Modern preschool education 2(98), 38-50 (2020) https://doi.org/10.24411/1997-9657-2020-10067

41. T.V. Kuzmicheva, Yu. A. Afonkina, Science and school 6, 158-164 (2020)

42. A.V. Khutorskoy, Bulletin of the Institute of Human Education 1, 6 (2020) https://eidos-institute.ru/journal/

43. A.Yu. Shemanov, D.E. Makaeva, Psychological Science and Education 8(1), 24-34 (2016)

44. V.G. Zakirova, E.L. Nikitina, International Journal of Environmental \& Science Education 11(8), 2099-2111 (2016)

45. N.J. Zollers, M.Yu, A.K. Ramanathan, International Journal of Qualitative Studies in Education 12(2), 157-174 (2010)

46. E.L. Ushakova Integration and inclusion: problems and perspectives. Special education and sociocultural integration 3, 288-293 (2020)

47. I.P. Pavlov, Full composition of writings (Nauka Publ., Moscow, 1949)

48. P. Lalwani, HRtechnologist.com https://www.hrtechnologist.com/articles/employee-engagement/linkedinglobal-talenttrends-2020-latest-hr-trends

49. Yu.V. Selivanova, D.V. Zaitsev, Special education and sociocultural integration 3, 235-245 (2020)

50. Creating an Inclusive Society: Practical Strategies to Promote Social Integration (UN, 2009) http://www.un.org/esa/socdev/egms/docs/2009/Ghana/inclusivesociety.pdf

51. M. Wolf, International Institute for labour studies. United Nations development program (UN Publ., Geneva, 1994)

52. L. Kendall, Cogent Education 33, 121-143 (2017)

53. T.M. Scott, K.L. Park, J. Swain-Bradway, E. Landers, International Journal of Behavioral Consultation and Therapy 3(2), 223-235 (2007)

54. T.E. Maltseva, Innovative features of the development of higher inclusive education (KnoRus Publ., Moscow, 2018)

55. D.A. Ivanov, Bulletin of Science and Creativity 4(64), 27-32 (2021)

56. E. Horn, Nmhc.Org (2018) https:// www.nmhc.org/news/nmhc-news/what-is-aninclusive-culture-and-do-you-have-one/

57. D. Mitchell, Effective pedagogical technologies of special and inclusive education (Perspective, Moscow, 2011)

58. Yu.A. Shulekina, D.E. Novikova, Bulletin of the Moscow City Pedagogical University. Series: Pedagogy and Psychology 4(54), 121-127 (2020)

59. I.A. Erina, S.N. Perederiy, L.N. Mokeeva, The world of science, culture, education 6(85), 169-170. (2020)

60. M.R. Arpentieva, I.V. Gorelova, K.G. Kassymova, S.V. Lavrinenko, K.A. Shumova, D.M. Malinichev, V.L. Simonov, A.V. Kosov, G.V. Garbuzova, O.P. Stepanova, Bulletin of the National Academy of Sciences of the Republic of Kazakhstan 1(383), 242-254 (2020)

61. S.V. Lavrinenko, I.V. Gorelova, G.K. Kassymova, O.V. Kubantseva, T.L. Khudyakova, I.V. Yusipova, D.M. Malinichev, L.B. Dykhan, G.A. Stepanova, M.R. Arpentieva, Bulletin of the National Academy of Sciences of the Republic of Kazakhstan 1(383), 264-276 (2020) 